\title{
Mesangial Cell-Specific Antibodies Are Central to the Pathogenesis of Lupus Nephritis
}

\author{
Guillaume Seret, ${ }^{1,2}$ Yannick Le Meur, ${ }^{1,2}$ Yves Renaudineau, ${ }^{1,3}$ and Pierre Youinou ${ }^{1,3}$ \\ ${ }^{1}$ EA2216 “Immunology \& Pathology” and IFR146 “ScInBios," European University of Brittany, 29200 Brest, France \\ ${ }^{2}$ Unit of Nephrology, Brest University Medical School Hospital, 29609 Brest, France \\ ${ }^{3}$ Laboratory of Immunology, Brest University Medical School Hospital, BP824, 29609 Brest, France
}

Correspondence should be addressed to Pierre Youinou, youinou@univ-brest.fr

Received 23 June 2011; Revised 31 August 2011; Accepted 4 October 2011

Academic Editor: Sara Marsal

Copyright (C) 2012 Guillaume Seret et al. This is an open access article distributed under the Creative Commons Attribution License, which permits unrestricted use, distribution, and reproduction in any medium, provided the original work is properly cited.

Not only is nephritis a common complaint in systemic lupus erythematosus, but it is also the most life-threatening complication of the disease. Anti-double-stranded DNA antibodies (Abs), which are found in up to $80 \%$ of these patients, might be nephritogenic per se. That is, they may cross-react with mesangial cell (MC) surface proteins, such as alpha-actinin and annexin A2, they may cross-react with mesangial matrix protein such as laminine and fibronectin, or they may recognize chromatin material previously deposited in the glomeruli. The consequence of the binding of anti-MC Abs may be their internalization, which results in activation and proliferation of these MCs. In turn, these activated MCs are suspected of promoting immune complex formation by sequestering and thereby protecting chromatin from degradation. The present paper will explain the mechanisms through which such autoAbs may initiate nephritis.

\section{Introduction}

Systemic lupus erythematosus (SLE) is a nonorgan-specific autoimmune disease, the hallmark of which is a vast array of antiself antibodies (autoAbs), and, among them, the whole range of antinuclear Abs (ANAs). The ensuing immune complexes (ICs) settle in the tissues and thereby subsequently contribute to local damage.

Most organs are at risk of being involved in this process at one time or another, given that the course of the disease consists of sequential flares and remissions. Estimates of the prevalence vary from 20 to 150 cases per 100,000 individuals, with the highest frequency in Afro-Caribbeans, followed by Asians, and far less frequent in Caucasians [1]. The maleto-female ratio rises to $1: 9$ during child-bearing age but diminishes thereafter.

In fact, the pathophysiology of SLE is so complicated that its development implicates multiple genes and entails a number of environmental factors (recognized or unknown). With regard to the genetics, predisposing genes are associated with the innate as well as the acquired immune responses. Of these, SLE can involve the antigen- (Ag-) presenting DR2 and DR3 HLA class II molecules, the lymphocyte activation markers, components of the classical complement activation pathway, various features involved in the processing of ICs, and interferon (IFN) signaling cascade members [2].

Lupus nephritis (LN) predominates as a cause of mortality in SLE and displays several epidemiological particularities [3]. For example, there exists an ethnic susceptibility, in that it develops in $20 \%$ of Caucasian patients compared with $50 \%$ of Asian patients. Whereas SLE is, by and large, more frequent in females than in males, the susceptibility for LN in Caucasians reaches $50-60 \%$ in males compared with 20 $35 \%$ in females. This complication arises usually within the first two years of the disease. Several gene polymorphisms have been claimed to favor LN (Table 1), and some SLEspecific autoAbs have been shown to recognize glomerular Ags (Table 2). Furthermore, it has been suggested that anti-double-stranded DNA (anti-dsDNA) Ab-induced renal failure could be linked to differences in the fine specificities of these autoAbs. Over several decades, a large body of work has been devoted to deciphering the anti-dsDNA Abs and to understand the deposition of anti-dsDNA/nucleosome ICs in the kidney, yet there are few reports available on 
TABLE 1: Genes associated with lupus nephritis (LN) [4-10].

\begin{tabular}{lcc}
\hline Gene & Function & Influence \\
\hline CD48 & Leucocyte adhesion & Protective effect \\
Fc RIIIA/IIA & Binding affinity & Susceptibility to SLE and LN \\
Kallikrein & Inflammation & Protective effect \\
IL-18 & Inflammation & Susceptibility to LN \\
Myeloperoxidase & Inflammation & Susceptibility to LN \\
TLR9 & Immune response & Susceptibility to LN \\
MBL2 & Complement & Susceptibility to LN \\
\hline
\end{tabular}

TABLe 2: Glomerular targets for anti-double-stranded (ds)-DNA antibodies [11, 12].

\begin{tabular}{lc}
\hline $\begin{array}{l}\text { Molecules that directly } \\
\text { cross-react with anti-dsDNA } \\
\text { antibodies }\end{array}$ & Cell type/glomerular matrix \\
\hline $\begin{array}{l}\text { Alpha-actinin } \\
\text { Annexin A2 }\end{array}$ & $\begin{array}{c}\text { Mesangial cells } \\
\text { Ribosomal P protein }\end{array}$ \\
Alpha-enolase & Mesangial cells, epithelial cells \\
Laminin & Mesangial cells, endothelial cells \\
Fibronectin & Glomerular matrix \\
Collagen & Glomerular matrix \\
Heparan sulfate & Glomerular matrix \\
Hyaluronic acid & Glomerular matrix \\
\hline
\end{tabular}

the recognition of glomerular structures, and even fewer studies on the recognition of mesangial cells (MCs). Our paper will, therefore, endeavour to provide glimpses into the mechanisms that may account for the development of nephritis in patients with SLE.

\section{Mesangial Cells}

2.1. Mesangial Cell Functions. Glomeruli are comprised of at least four cell types: MCs, endothelial cells (ECs), and podocytes plus parietal cells, both of an epithelial nature and the later shaping the Bowman's capsule (Figure 1). Filtration through the glomerular barrier is under the control of MCs plus podocytes, along with renal blood flow by contracting the GBM [13]. The glomerular blood-urine barrier superimposes three layers: fenestrae between adjacent ECs, the glomerular basal membrane (GBM), and the slit diaphragm mid podocytes.

The MCs are specialized smooth muscle cells, of which the contractility depends upon vasoactive molecules, such as angiotensin II and endothelin-1. They possess additional capabilities, including support of the glomerular capillaries. MCs synthesize and renew their own extracellular matrix, which is distinct from the GBM. The mesangial matrix is made up of fibronectin, collagen II, collagen IV, laminin, entactin, nidogen, and perlecan. The sialoglycoprotein fibronectin is located on the MC surface and is required for attachment of circulating components, including chromatin, to MCs and ECs. The other sialoglycoprotein laminin and

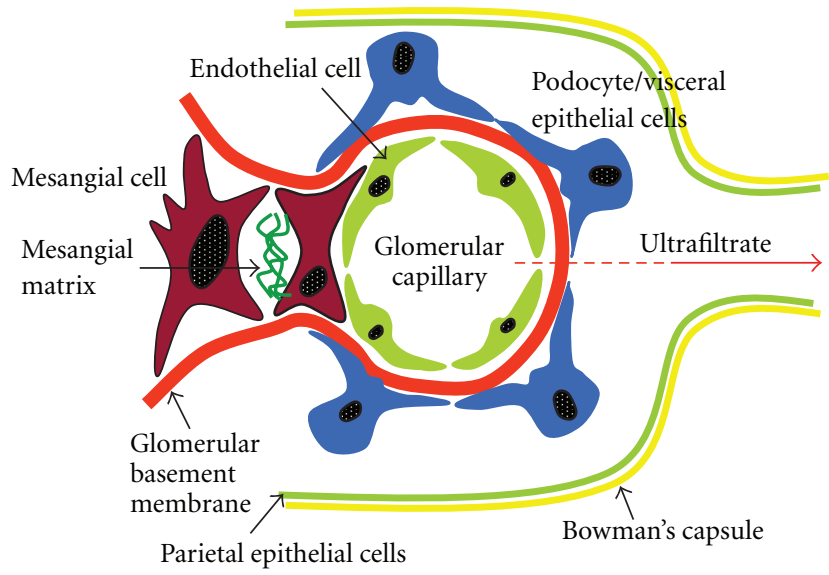

FIGURE 1: Schematic representation of the different cell types of the glomerular filtration barrier.

the sulphated glycoprotein entactin are equally implicated in this event. Other important functions for MCs are their phagocytic capacity to take up apoptotic cells and their capacity to prevent accumulation of ICs by bringing into play nonspecific mechanisms, such as pinocytosis and phagocytosis, and specific mechanisms, such as receptordependent processes. Once activated, MCs secrete proinflammatory cytokines (e.g., interleukin (IL)-1, IL-6, IL12 , and IFN- $\gamma$ ), growth factors (e.g., transforming growth factor (TGF)- $\beta$ and vascular endothelial growth factor), and metalloproteinases (e.g., metalloproteinase (MMP)-2 and MMP-9). All these effects are tightly regulated in normal cells and may be markedly altered by glomerular pathology.

2.2. Mesangial Cells and Kidney Diseases. A variety of ICs, which are lacking in normal mesangium, become detectable in the kidneys of patients with a variety of diseases, such as LN, IgA nephropathy (IgAN), Clq nephropathy, and mild postinfectious glomerulonephritis (GN). Such patients often present with hematuria, associated with proteinuria at the nephrotic syndrome stage. Much uncertainty surrounds abnormalities of MCs in ICs deposition. Several mechanisms are, in fact, supposed to prevent ICs access into the mesangium. They include the endothelial barrier itself, the effect of a protective glycocalyx, and the recycling capacity of the podocytes that express the neonatal receptor for IgG (FcRn) [14]. The immunoglobulin-specific MC receptor 
remains a matter of debate, given that the mesangial Fcgamma receptors are dispensable for kidney injury as well as for cellular activation [15]. Alternatively, nonconventional receptors have been proposed. On the front line of the pathophysiology of IgAN is the transferring receptor, referred to as CD71 [16-18]. The IgA-IgG/CD71 complexes are crucial [19], as suggested by the fact that blocking CD71 with a related monoclonal $\mathrm{Ab}(\mathrm{mAb})$ inhibits $\mathrm{MC}$ proliferation and cytokine production, namely, IL- 6 and TGF- $\beta$. In addition, IgA and IgG are associated with the complement fraction C3 [20] and the mannose-binding lectin in the mesangium, highlighting the relevance of the complement lectin pathway to the development of such GNs.

Of note, proliferation of MCs and expansion of the mesangial matrix may take place in the absence of ICs. In this context, different forms of glomerular damage develop, namely, diabetic and amyloid nephropathies. In the course of diabetic nephropathy, elevated plasma levels of glucose contribute to the induction of nitric oxide synthase (iNOS), which in turn activate protein kinase C (PKC), mitogen-activated protein kinases (MAPK), and phosphatidyl inosytol-3 kinase/Akt [21]. As a result, fibronectin, collagen IV, and TGF- $\beta$ synthesis are upregulated, leading to the development of fibrosis and resulting in end-stage renal failure. Actually, such is the usual outcome of a large number of GNs.

\section{Mesangial Cells and Lupus Nephritis}

3.1. Pathogenic Models. Anti-dsDNA Abs are relevant to the diagnosis of SLE and instrumental in the development of LN. However, the mechanism by which they contribute to the $\mathrm{GN}$ is far from clear, considering the fact that not all Abs to dsDNA are able to cause tissue damage to a similar extent. A popular view has been that GN results from ICs associating with nucleosomes released from apoptotic/necrotic cells that have bound anti-dsDNA/chromatin Abs. A wealth of evidence supports this simplistic model. For example, renal flares are preceded by a rise of the anti-dsDNA Ab levels in plasma and a reciprocal reduction in levels of free DNA [22]. In $\mathrm{LN}$, the anti-dsDNA Ab/chromatin complexes are seen as electron-dense structures in the mesangial matrix and move to the GBM as soon as the disease is established [23]. An acquired renal DNase1 deficiency, coupled with chromatin sequestration by matrix protein accumulation, amplifies the process by offering more target Ags to anti-dsDNA Abs [24]. Nonetheless, this mechanism cannot be responsible for the whole process, since analysis of kidney-eluted IgG has revealed that those Abs binding to dsDNA represent as little as $10 \%$ of the total bulk of IgG [25]. Additional points to keep in mind are that only a minute fraction of antidsDNA Abs are pathogenic when transferred to experimental animals, and LN could develop in the absence of anti-dsDNA Ab. Last but not least, differences between nephritogenic and nonnephritogenic anti-dsDNA Abs are unrelated to structural differences in class, subclass, or avidity (Table 3 ). Rather, they consist of varying capacities to react with MC products in the absence of a DNA docking site [26]. The generation of nephritogenic $\mathrm{Ab}$ is incompletely understood and possibly results from an antigen-dependent stepwise process due to isotype switching and somatic mutations that would result in acquisition of cross-reactivity and highaffinity binding. Stimulation may be sustained by dsDNA along with a glomerular antigen or more probably shared epitopes. It is striking to observe that only one mutation can change the affinity, the cross-reactivity properties, and the kidney binding localization of a pathogenic anti-dsDNA Ab.

Accordingly, the concept has been put forward that anti-dsDNA Abs launch the GN process through crossreaction with cell-surface and matrix components. So far, several glomerular Ags have indeed been suspected as serving as targets for anti-dsDNA Abs [11, 12]. To reconcile the theory of active cross-reactivity and the concept of passive IC deposition, we reasoned that neither is exclusive and speculated that both are ordered, in that $\mathrm{Ab}$ glomerular recognition precedes anti-dsDNA $\mathrm{Ab} /$ chromatin deposition $[27,30]$.

3.2. Histology. To account for so much variation in the clinical and histological patterns, the LN histopathological abnormalities have been classified into six classes. Based on the criteria proposed by the International Society of Nephrology/Renal Pathology Society (ISN/RPS) in 2003 [31], they include the morphology of the lesions, their mesangial, endothelial and epithelial extent, the Ab deposition, and the distinction between active and chronic lesions. Briefly, class I histopathological damage corresponds to mesangial deposits, but renal symptoms may be absent. Class II refers to mesangial proliferation, and mild proteinuria and microscopic hematuria characterize these patients. The renal prognostic value is often excellent but may evolve through mesangial and endothelial lesions [32, 33]. Class III and class IV imply glomerulus antibody deposition. In essence, class III LN (less than $50 \%$ of the glomeruli are impacted) manifest hematuria, proteinuria, nephritic syndrome, and occasionally hypertension. Class IV (more than $50 \%$ of the glomeruli) characterizes diffuse LN and comprises segmental and global forms, according to the severity of glomerular lesions. Hematuria, massive proteinuria, nephritic syndrome, and acute renal failure occur in $16 \%$ of class IV patients. Class V corresponds to immunecomplex-derived membranous nephritis. The lesions display global or segmental distribution, although more than $50 \%$ of the capillary basement membrane is involved in either case. Clinical presentations include proteinuria (typically at a nephritic range), with hematuria but usually without renal insufficiency. Finally, class VI lesions correspond to the last stage of the disease, resulting from the alteration between flares and pauses, leading to overt renal failure, and substantiated by vascular sclerosis, tubulointerstitial scarring, and glomerular sclerosis. However, these clinical features are not well associated with the classification since, histologically, severe LN may be clinically silent. Besides these well-documented types of damage, SLE yields a broad variety of vascular lesions, which are neglected in the ISN/RPS 2003 classification. 
TABLE 3: Nephritogenic and cross-reactive anti-dsDNA Ab properties [26-29].

\begin{tabular}{lccc}
\hline & Non-nephritogenic anti-dsDNA Ab & Nephritogenic anti-dsDNA Ab & Cross-reactive anti-dsDNA Ab \\
\hline Class & IgG M and A & IgG mainly & IgG mainly \\
Somatic mutations & No & Yes & Yes \\
Affinity & Low & High & High \\
Cross-reactivity & No & Yes & Yes \\
Living cell internalization & No & Yes & suspected \\
Glomerular direct binding & No & Yes & Yes \\
Proteinuria & No & Yes & mainly \\
\hline
\end{tabular}

3.3. Mesangial Cells in Lupus Nephritis. Aberrant proliferation, apoptosis, and activation of MCs are common findings during LN. As a consequence, numerous genes have been demonstrated by immunohistochemistry and/or molecular biology to be upregulated during LN [34-38]. These include genes for survival and apoptotic factors (Bcl-2, Fas, FasL), chemokines that attract inflammatory cells (CCL5, CXCL1), inflammatory mediators (ROS, iNOS), proinflammatory type 1 cytokines (IFN- $\gamma$, IL-12, IL-6), mesangial matrix synthesis (fibronectin), collagen IV degradation (MMP-2 and MMP-9), and chromatin accumulation (DNase1 downregulation). MC pathogenicity could be attributed in part to anti-dsDNA activity since anti-dsDNA Abs stimulate MCs to produce chemokines (MCP-1, CCL-5), matrix metalloproteinases (MMP-2, MMP-9), reactive oxygen (iNOS), cytokines (IL-6, TGF- $\beta$ ), and lipocalin-2/NGAL [39, 40]. Although incompletely characterized, such effects are related in part to the activation of the PKC and MAPK pathways.

\section{Autoantibodies and Lupus Nephritis}

4.1. Antiglomerular Antibodies. ANAs may arise well before the development of overt disease, with a crescendo of more and more SLE-specific autoAbs being produced over 10 years [41]. The earliest ANAs are anti-Ro/Sicca Syndrome (SS)-A and anti-La/SSB Abs, on average 3.7 years before, followed by anti-dsDNA Abs, on average 2.2 years before, and the antiSmith (Sm) ribonucleoprotein (RNP) Abs, on average 0.9 years before the advent of clinical symptoms. Intriguingly, the presence of anti-Ro/La/Sm RNP Abs and IgM anti$\beta 2$ glycoprotein I could well protect the patient from LN $[42,43]$. On the other hand, high-titer and high-avidity antidsDNA Abs have been reported to be linked to active disease and suspected to be associated with LN.

Typically, ICs from patients suffering LN contain IgG, IgM, and IgA, along with the complement fractions $\mathrm{C} 1 \mathrm{q}$ and C3. In $90 \%$ of the cases, IgG predominates over IgM and IgA which are associated with $60 \%$ of the IgG-containing ICs. These latter abnormalities are exceptional in diseases other than LN. With regard to fibrin and fibrinogen, they characterize crescent and necrotizing segments. Specificity analysis of Abs eluted from the kidneys unveils a broad range of reactivities. These are chromatin, $\alpha$-actinin, collagen, entactin, fibrinogen, laminin, proteoglycan, phospholipids (PLs), myosin, RNP, and so on [25]. Similarly, microarray technology has distinguished two main clusters of serum IgM and IgG autoAbs in the serum of patients with LN, based on their specificities. One is directed to chromatin and the other to the glomerulus [44]. Their DNA dependence has been tested using DNase-1 pretreatment, and the results of these experiments indicated that $20 \%$ of the Abs binding to the glomeruli were DNA independent.

The observation that some anti-dsDNA Abs attach directly to renal tissues, and more particularly to MCs, raises the question as to whether or not any target Ag is specific for such LN-associated autoAbs. This issue has been addressed using several approaches. First, anti-dsDNA mAbs have been injected into nonautoimmune mice and shown to cause a LN-like disease [26, 45]. Similarly, immunization with a peptide for anti-dsDNA Ab can initiate $\mathrm{LN}$ in Balb/c mice [46]. Of note, site-directed mutagenesis of the nephritogenic antidsDNA mAb R4A alters not only its affinity to dsDNA, but also its cross-reactivity with glomerular Ags. Cross-reactivity can even shift from the glomerular to the tubular area [28]. Anti-dsDNA Ab point mutations may thus influence the evolution of LN over time. The second approach relied on glomerular-derived peptides which were examined for their interactions with anti-dsDNA Abs [47]. The third approach used human sera purified from LN patients and those which recognized human MCs as well [48]. This approach enabled the discovery of three main specific MC targets at 42,63, and $74 \mathrm{kDa}$ when using anti-dsDNA and non-anti-dsDNA purified Abs from these patients. DNasel pretreatment did not affect their binding. Furthermore, purified antihuman MC Abs are likely to be internalized and thus able to encourage iNOS activation, MC proliferation, and matrix synthesis [12]. As recently documented [49], antihuman MC Abs are associated with $84 \%$ of active LN compared with $43 \%$ of inactive LN.

\subsection{Antimesangial Cells Antibodies}

4.2.1. Anti- $\alpha$-Actinin Antibodies. Glomerular $\alpha$-actinin is expressed on the surface of MCs and podocytes but not on that of the GBM. This actin-binding protein belongs to the superfamily of cytoskeletal proteins. It is comprised of four isoforms, and mutations in the fourth isoform can lead to focal and segmental glomerulosclerosis [50].

That $\alpha$-actinin can be targeted by anti-dsDNA Abs has also been demonstrated. This is tied to the fact that injection of anti-dsDNA mAb into RAG-1-deficient mice induces 
a proteinuria with glomerular deposits in these animals. Cross-reaction with $\alpha$-actinin [26] or laminin-1 [51] provided the anti-dsDNA Abs with the capacity to impair the renal function. This view was supported by the finding that, once bound to MCs, anti-dsDNA R4A mAbs [29] upregulate the production of iNOS and proinflammatory chemokines [39]. Demonstration of the reality of pathogenic $\alpha$-actinin, which is worthy of pursuit in the future, was thus reinforced by the observation that $\alpha$-actinin-immunized normal mice mounted an anti- $\alpha$-actinin $\mathrm{Ab}$ response first and then produced anti- $\alpha$-actinin and anti-chromatin Abs, along with advancing stages of the LN-like disease [52]. In SLE patients, the anti- $\alpha$-actinin Ab production culminates early at the initiation of the LN, but their titers drop dramatically after treatment is initiated, that is, when the disease activity is reduced. We must admit that, in contrast to the anti-dsDNA/chromatin activity, the results of the detection of these autoAbs are inconsistent [53-56]. Of interesting note, the anti- $\alpha$-actinin response is related to the actin-binding site of $\alpha$-actinin [54, 57].

4.2.2. Antiannexin A2 Antibodies. Annexin A2 is a calciumdependent PL-binding protein expressed on the surface of phagocytic cells, such as macrophages, ECs, and MCs. This protein is pivotal in the regulation of MC proliferation, activation, apoptosis, and in coagulation by recruiting plasminogen and tissue plasminogen activator.

In $\mathrm{LN}, \mathrm{IgG}$, and $\mathrm{C} 3$, deposits colocalize with annexin A2 in the glomeruli but, surprisingly, not in the tubuli [12]. Annexin A2-dependence has been tested by gene silencing using RNA interference technology, as an attempt to establish that its downregulation prevents anti-dsDNA Ab binding, $\mathrm{Ab}$ internalization, and MC activation. Supporting this view, a positive antiannexin $\mathrm{A} 2 \mathrm{Ab}$ test is associated with active LN and thrombosis $[12,58]$. The abnormality is related to the activation of the tissue factor on ECs and monocytes, which is in accord with the detection of anti-annexin A2 Ab in $40 \%$ of patients with the anti-PL syndrome.

\subsection{Antimatrix Antibodies}

4.3.1. Antilaminin Antibodies. Laminin belongs to the mesangial matrix. Laminin-1, which is the most abundant isoform, is derived from MCs. It is overexpressed and hence becomes detectable in the GBM during $\mathrm{LN}$ and at the periphery of end-stage sclerotic lesions [59]. It is, therefore, of no surprise that antilaminin Abs are found during LN and that their levels correlate with the disease activity and proteinuria [51]. Notwithstanding, they are not specific for SLE, being also detected in recurrent miscarriages, infertility and pemphigus. The main epitope recognized by antilaminin-1 Ab corresponds to the binding site of laminin to the basement membrane receptors.

4.3.2. Antifibronectin Antibodies. Fibronectin is absent from normal mesangial matrix but overexpressed in LN and colocalized with IgG/chromatin ICs in the mesangium. The prevalence of antifibronectin Abs ranges from 30 to $80 \%$

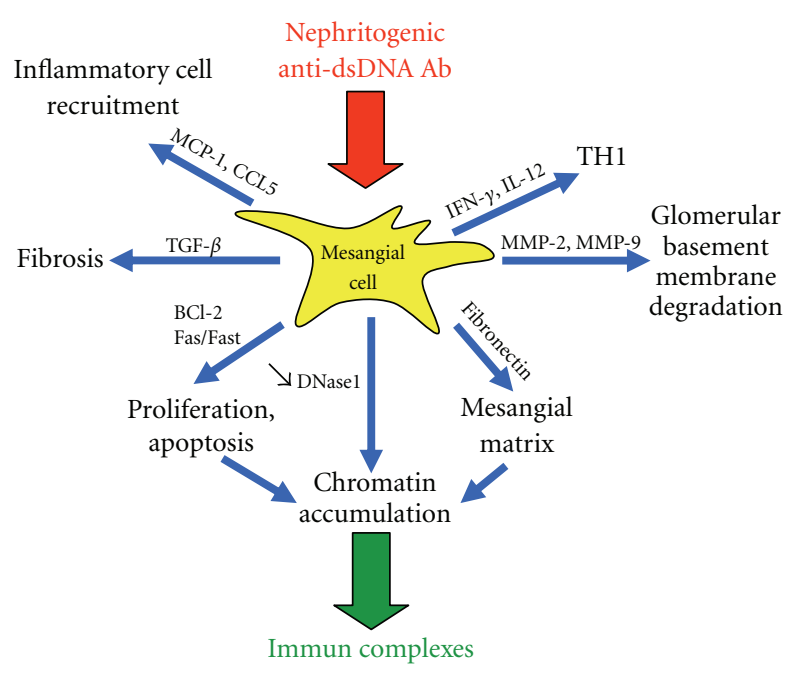

FIGURE 2: A working model of mesangial cell (MC) stimulation by nephritogenic anti-dsDNA $\mathrm{Ab}$ in lupus nephritis leading to accumulation of immune complexes.

in patients with SLE, and from 15 to $40 \%$ in those with rheumatoid arthritis and other systemic vasculitis. Although nonspecific for any disease, antifibronectin Ab levels correlate with activity in patients with SLE. In this regard, one of the most efficient drugs to treat LN, mycophenolate mofetil, prevents anti-dsDNA Ab-induced fibronectin production by MCs. In other words, the drug contributes to reduce IC deposition [40].

4.4. Miscellaneous Antibodies. Involved in the elongation step of protein synthesis when associated with the large ribosomal subunit, the ribosomal serine phosphorylated proteins $\mathrm{P} 0$, P1, and P2 appear on the membrane of multiple cells, including MCs and blood cells of patients with SLE. The reported prevalence of antiribosomal Abs varies from 5 to $45 \%$ in SLE, more often in Asian patients than in Caucasian and African patients [60]. In SLE, they are restricted to active disease, with kidney, hepatic, and neuropsychiatric complications. Once again, high-affinity anti-dsDNA Abs cross-react with ribosomal proteins.

Alpha-enolase appears on the surface of MCs and podocytes and in the tubuli from patients with LN. In this setting, it acts as a glycolytic enzyme and a receptor for plasminogen. The anti- $\alpha$-enolase Ab test is positive in SLE patients but is not associated with LN and flares [61]. Alphaenolase has been identified as an autoAg in other diseases, such as Behcet's disease, retinopathy, and severe asthma.

\section{Conclusion}

Whereas compelling evidence in LN suggests a pathogenic role for anti-dsDNA Abs, their detailed mechanisms of action are not restricted to IC formation. As illustrated in Figure 2, we propose that, among anti-dsDNA Abs, a minute fraction of anti-dsDNA Abs stimulate MCs to produce cytokines, chemokines, and matrix metalloproteinases important in the initiation of the inflammatory process. In addition, such 
activation is associated with proliferation and apoptosis, matrix protein accumulation, and a reduction of DNase1 activity that would, in turn, contribute to the formation of anti-dsDNA Ab chromatin/ICs in the mesangium and later in the GBM that characterize severe LN. Furthermore, while the focus of this paper is on MCs, it should be mentioned that antigens could be displayed by other glomerular cells as well, including podocytes. As a consequence, the pathogenicity of these Abs would be enhanced by targeting more than one cell type.

\section{Acknowledgments}

Thanks are due to Simone Forest and Geneviève Michel for their help with the typing of the paper. Thanks are due also to Dr. Wesley H. Brooks (H. Lee Moffitt Cancer Center and Research Institute, Tampa, Fla) for editorial assistance. G. Seret was supported by an "année recherche" grant from the "Direction des Affaires Sanitaires et Sociales de Bretagne".

\section{References}

[1] A. T. Borchers, S. M. Naguwa, Y. Shoenfeld, and M. E. Gershwin, "The geoepidemiology of systemic lupus erythematosus," Autoimmunity Reviews, vol. 9, no. 5, pp. A277-A287, 2010.

[2] A. Delgado-Vega, E. Sánchez, S. Löfgren, C. CastillejoLópez, and M. E. Alarcón-Riquelme, "Recent findings on genetics of systemic autoimmune diseases," Current Opinion in Immunology, vol. 22, no. 6, pp. 698-705, 2010.

[3] V. A. Seligman, R. F. Lum, J. L. Olson, H. Li, and L. A. Criswell, "Demographic differences in the development of lupus nephritis: a retrospective analysis," American Journal of Medicine, vol. 112, no. 9, pp. 726-729, 2002.

[4] A. E. Koh, S. W. Njoroge, M. Feliu et al., "The SLAM family member CD48 protects lupus-prone mice from autoimmune nephritis," Journal of Autoimmunity, vol. 37, no. 1, pp. 48-57, 2011.

[5] Z. T. Chu, N. Tsuchiya, C. Kyogoku et al., "Association of Fc-gamma receptor IIb polymorphism with susceptibility to systemic lupus erythematosus in Chinese: a common susceptibility gene in the Asian populations," Tissue Antigens, vol. 63, no. 1, pp. 21-27, 2004.

[6] Q. Z. Li, J. Zhou, R. Yang et al., "The lupus-susceptibility gene kallikrein downmodulates antibody-mediated glomerulonephritis," Genes and Immunity, vol. 10, no. 5, pp. 503-508, 2009.

[7] D. Y. Chen, C. W. Hsieh, K. S. Chen, Y. M. Chen, F. J. Lin, and J. L. Lan, "Association of interleukin-18 promoter polymorphisms with WHO pathological classes and serum IL18 levels in Chinese patients with lupus nephritis," Lupus, vol. 18, no. 1, pp. 29-37, 2009.

[8] H. Bouali, P. Nietert, T. M. Nowling et al., "Association of the G-463A myeloperoxidase gene polymorphism with renal disease in African Americans with systemic lupus erythematosus," Journal of Rheumatology, vol. 34, no. 10, pp. 2028-2034, 2007.

[9] P. L. De Jager, A. Richardson, T. J. Vyse, and J. D. Rioux, "Genetic variation in toll-like receptor 9 and susceptibility to systemic lupus erythematosus," Arthritis and Rheumatism, vol. 54, no. 4, pp. 1279-1282, 2006.
[10] P. Sandrin-Garcia, L. A. C. Brandão, A. V.C. Coelho et al., "Mannose binding lectin gene (MBL2) functional polymorphisms are associated with systemic lupus erythematosus in southern Brazilians," Human Immunology, vol. 72, no. 6, pp. 516-521, 2011.

[11] Y. Renaudineau, B. Deocharan, S. Jousse, E. Renaudineau, C. Putterman, and P. Youinou, "Anti-alpha-actinin antibodies: a new marker of lupus nephritis," Autoimmunity Reviews, vol. 6, no. 7, pp. 464-468, 2007.

[12] S. Yung, K. F. Cheung, Q. Zhang, and T. M. Chan, "AntidsDNA antibodies bind to mesangial annexin II in lupus nephritis," Journal of the American Society of Nephrology, vol. 21, no. 11, pp. 1912-1927, 2010.

[13] D. Schlöndorff and B. Banas, "The mesangial cell revisited: no cell is an island," Journal of the American Society of Nephrology, vol. 20, no. 6, pp. 1179-1187, 2009.

[14] S. Akilesh, T. B. Huber, H. Wu et al., "Podocytes use FcRn to clear IgG from the glomerular basement membrane," Proceedings of the National Academy of Sciences of the United States of America, vol. 105, no. 3, pp. 967-972, 2008.

[15] R. M. Tarzi, K. A. Davies, M. G. Robson et al., "Nephrotoxic nephritis is mediated by $\mathrm{Fc}$-gamma receptors on circulating leukocytes and not intrinsic renal cells," Kidney International, vol. 62, no. 6, pp. 2087-2096, 2002.

[16] J. Berger and N. Hinglais, "Intercapillary deposits of IgA-IgG," Journal d'Urologie et de Nephrologie, vol. 74, no. 9, pp. 694695, 1968.

[17] Y. Hiki, H. Iwase, M. Saitoh et al., "Reactivity of glomerular and serum IgA1 to jacalin in IgA nephropathy," Nephron, vol. 72, no. 3, pp. 429-435, 1996.

[18] I. C. Moura, M. Arcos-Fajardo, A. Gdoura et al., "Engagement of transferrin receptor by polymeric IgA1: evidence for a positive feedback loop involving increased receptor expression and mesangial cell proliferation in IgA nephropathy," Journal of the American Society of Nephrology, vol. 16, no. 9, pp. 26672676, 2005.

[19] I. C. Moura, M. N. Centelles, M. Arcos-Fajardo et al., "Identification of the transferrin receptor as a novel immunoglobulin IgA1 receptor and its enhanced expression on mesangial cells in IgA nephropathy," Journal of Experimental Medicine, vol. 194, no. 4, pp. 417-425, 2001.

[20] M. Endo, H. Ohi, I. Ohsawa, T. Fujita, M. Matsushita, and T. Fujita, "Glomerular deposition of mannose-binding lectin indicates a novel mechanism of complement activation in IgA nephropathy," Nephrology Dialysis Transplantation, vol. 13, no. 8, pp. 1984-1990, 1998.

[21] N. Kashihara, Y. Haruna, V. K. Kondeti, and Y. S. Kanwar, "Oxidative stress in diabetic nephropathy," Current Medicinal Chemistry, vol. 17, no. 34, pp. 4256-4269, 2010.

[22] A. Hedberg, E. S. Mortensen, and O. P. Rekvig, "Chromatin as a target antigen in human and murine lupus nephritis," Arthritis Research and Therapy, vol. 13, article 214, 2011.

[23] M. Kalaaji, K. A. Fenton, E. S. Mortensen et al., "Glomerular apoptotic nucleosomes are central target structures for nephritogenic antibodies in human SLE nephritis," Kidney International, vol. 71, no. 7, pp. 664-672, 2007.

[24] K. Fenton, S. Fismen, A. Hedberg et al., "Anti-dsDNA antibodies promote initiation, and acquired loss of renal dnase 1 promotes progression of lupus nephritis in autoimmune (NZBxNZW)F1 mice," PLoS One, vol. 4, no. 12, Article ID e8474, 2009. 
[25] M. Mannik, C. E. Merrill, L. D. Stamps, and M. H. Wener, "Multiple autoantibodies form the glomerular immune deposits in patients with systemic lupus erythematosus," Journal of Rheumatology, vol. 30, no. 7, pp. 1495-1504, 2003.

[26] G. Mostoslavsky, R. Fischel, N. Yachimovich, S. H. Sacks et al., "Lupus anti-DNA autoantibodies cross-react with a glomerular structural protein: a case for tissue injury by molecular mimicry," European Journal of Immunology, vol. 31, no. 4, pp. 1221-1227, 2001.

[27] C. Hanrotel-Saliou, I. Segalen, Y. Le Meur, P. Youinou, and Y. Renaudineau, "Glomerular antibodies in lupus nephritis," Clinical Reviews in Allergy and Immunology, vol. 40, pp. 151$158,2011$.

[28] J. B. Katz, W. Limpanasithikul, and B. Diamond, "Mutational analysis of an autoantibody: differential binding and pathogenicity," Journal of Experimental Medicine, vol. 180, no. 3, pp. 925-932, 1994.

[29] B. Deocharan, X. Qing, J. Lichauco, and C. Putterman, "Alphaactinin is a cross-reactive renal target for pathogenic anti-DNA aptibodies," Journal of Immunology, vol. 168, no. 6, pp. 3072 $3078,2002$.

[30] M. C. J. van Bruggen, C. Kramers, M. N. Hylkema, R. J. T. Smeenk, and J. H. M. Berden, "Significance of anti-nuclear and anti-extracellular matrix autoantibodies for albuminuria in murine lupus nephritis; a longitudinal study on plasma and glomerular eluates in MRL/l mice," Clinical and Experimental Immunology, vol. 105, no. 1, pp. 132-139, 1996.

[31] J. J. Weening, V. D. D’Agati, M. M. Schwartz et al., “The classification of glomerulonephritis in systemic lupus erythematosus revisited," Journal of the American Society of Nephrology, vol. 15, no. 2, pp. 241-250, 2004.

[32] S. G. Lee, Y. M. Cho, M. W. So et al., "ISN/RPS 2003 class II mesangial proliferative lupus nephritis: a comparison between cases that progressed to class III or IV and cases that did not," Rheumatology International. In press.

[33] M. E. Zabaleta-Lanz, L. E. Muñoz, F. J. Tapanes et al., "Further description of early clinically silent lupus nephritis," Lupus, vol. 15, no. 12, pp. 845-851, 2006.

[34] N. A. Fathi, M. R. Hussein, H. I. Hassan, E. Mosad, H. Galal, and N. A. Afifi, "Glomerular expression and elevated serum Bcl-2 and Fas proteins in lupus nephritis: preliminary findings," Clinical and Experimental Immunology, vol. 146, no. 2, pp. 339-343, 2006.

[35] S. D. Marks, S. J. Williams, K. Tullus, and N. J. Sebire, "Glomerular expression of monocyte chemoattractant protein-1 is predictive of poor renal prognosis in paediatric lupus nephritis," Nephrology Dialysis Transplantation, vol. 23, no. 11, pp. 3521-3526, 2008.

[36] S. Segerer, A. Henger, H. Schmid et al., "Expression of the chemokine receptor CXCR1 in human glomerular diseases," Kidney International, vol. 69, no. 10, pp. 1765-1773, 2006.

[37] L. Zheng, R. Sinniah, and S. I. Hsu, "Renal cell apoptosis and proliferation may be linked to nuclear factor-kappaB activation and expression of inducible nitric oxide synthase in patients with lupus nephritis," Human Pathology, vol. 37, no. 6, pp. 637-647, 2006.

[38] A. A. Tveita, O. P. Rekvig, and S. N. Zykova, "Increased glomerular matrix metalloproteinase activity in murine lupus nephritis," Kidney International, vol. 74, no. 9, pp. 1150-1158, 2008.

[39] X. Qing, J. Zavadil, M. B. Crosby et al., "Nephritogenic antiDNA antibodies regulate gene expression in MRL/lpr mouse glomerular mesangial cells," Arthritis and Rheumatism, vol. 54, no. 7, pp. 2198-2210, 2006.
[40] S. Yung, Q. Zhang, C. Z. Zhang, W. C. Kwok, L. L. Sing, and M. C. Tak, "Anti-DNA antibody induction of protein kinase $\mathrm{C}$ phosphorylation and fibronectin synthesis in human and murine lupus and the effect of mycophenolic acid," Arthritis and Rheumatism, vol. 60, no. 7, pp. 2071-2082, 2009.

[41] M. R. Arbuckle, M. T. McClain, M. V. Rubertone et al., "Development of autoantibodies before the clinical onset of systemic lupus erythematosus," The New England Journal of Medicine, vol. 349, no. 16, pp. 1526-1533, 2003.

[42] F. J. Tápanes, M. Vásquez, R. Ramírez, C. Matheus, M. A. Rodríguez, and N. Bianco, "Cluster analysis of antinuclear autoantibodies in the prognosis of SLE nephropathy: are antiextractable nuclear antibodies protective?" Lupus, vol. 9, no. 6, pp. 437-444, 2000.

[43] T. Mehrani and M. Petri, "IgM anti- $\beta 2$ glycoprotein I is protective against lupus nephritis and renal damage in systemic lupus erythematosus," Journal of Rheumatology, vol. 38, no. 3, pp. 450-453, 2011.

[44] Q. Z. Li, C. Xie, T. Wu et al., "Identification of autoantibody clusters that best predict lupus disease activity using glomerular proteome arrays," Journal of Clinical Investigation, vol. 115, no. 12, pp. 3428-3439, 2005.

[45] B. Gaynor, C. Putterman, P. Valadon, L. Spatz, M. D. Scharff, and B. Diamond, "Peptide inhibition of glomerular deposition of an anti-DNA antibody," Proceedings of the National Academy of Sciences of the United States of America, vol. 94, no. 5, pp. 1955-1960, 1997.

[46] C. Putterman and B. Diamond, "Immunization with a peptide surrogate for double-stranded DNA induces autoantibody production and renal immunoglobulin deposition," Journal of Experimental Medicine, vol. 188, no. 1, pp. 29-38, 1998.

[47] H. Amital, M. Heilweil, R. Ulmansky et al., "Treatment with a laminin-derived peptide suppresses lupus nephritis," Journal of Immunology, vol. 175, no. 8, pp. 5516-5523, 2005.

[48] H. Du, M. Chen, Y. Zhang, M. H. Zhao, and H. Y. Wang, "Cross-reaction of anti-DNA autoantibodies with membrane proteins of human glomerular mesangial cells in sera from patients with lupus nephritis," Clinical and Experimental Immunology, vol. 145, no. 1, pp. 21-27, 2006.

[49] T. M. Chan, J. K. H. Leung, S. K. N. Ho, and S. Yung, "Mesangial cell-binding anti-DNA antibodies in patients with systemic lupus erythematosus," Journal of the American Society of Nephrology, vol. 13, no. 5, pp. 1219-1229, 2002.

[50] J. M. Kaplan, S. H. Kim, K. N. North et al., "Mutations in ACTN4, encoding alpha-actinin-4, cause familial focal segmental glomerulosclerosis," Nature Genetics, vol. 24, no. 3, pp. 251-256, 2000.

[51] H. Amital, M. Heilweil-Harel, R. Ulmansky et al., "Antibodies against the VRT101 laminin epitope correlate with human SLE disease activity and can be removed by extracorporeal immunoadsorption," Rheumatology, vol. 46, no. 9, pp. 14331437, 2007.

[52] B. Deocharan, Z. Zhou, K. Antar et al., "Alpha-actinin immunization elicits anti-chromatin autoimmunity in nonautoimmune mice," Journal of Immunology, vol. 179, no. 2, pp. 1313-1321, 2007.

[53] S. Croquefer, Y. Renaudineau, S. Jousse et al., "The anti-alphaactinin test completes anti-DNA determination in systemic lupus erythematosus," Annals of the New York Academy of Sciences, vol. 1050, pp. 170-175, 2005.

[54] Y. Renaudineau, S. Croquefer, S. Jousse et al., "Association of alpha-actinin-binding anti-double-stranded DNA antibodies with lupus nephritis," Arthritis and Rheumatism, vol. 54, no. 8, pp. 2523-2532, 2006. 
[55] D. Cornec, G. E. Cornec-Le, Z. Segalen et al., "Which autoantibodies announce that lupus nephritis is on the way?" International Journal of Clinical Rheumatology, vol. 4, no. 3, pp. 287-295, 2009.

[56] J. J. Manson, A. Ma, P. Rogers et al., "Relationship between anti-dsDNA, anti-nucleosome and anti-alpha-actinin antibodies and markers of renal disease in patients with lupus nephritis: a prospective longitudinal study," Arthritis Research \& Therapy, vol. 11, no. 5, p. R154, 2009.

[57] G. Guéguen, G. Dalekos, J. B. Nousbaum et al., "Double reactivity against actin and alpha-actinin defines a severe form of autoimmune hepatitis type 1," Journal of Clinical Immunology, vol. 26, no. 6, pp. 495-505, 2006.

[58] G. Cesarman-Maus, N. P. Ríos-Luna, A. B. Deora et al., "Autoantibodies against the fibrinolytic receptor, annexin 2, in antiphospholipid syndrome," Blood, vol. 107, no. 11, pp. 43754382, 2006.

[59] C. J. Kootstra, E. C. Bergijk, A. Veninga et al., "Qualitative alterations in laminin expression in experimental lupus nephritis," American Journal of Pathology, vol. 147, no. 2, pp. 476-488, 1995.

[60] M. Reichlin, "Autoantibodies to the ribosomal P proteins in systemic lupus erythematosus," Clinical and Experimental Medicine, vol. 6, no. 2, pp. 49-52, 2006.

[61] M. Mosca, D. Chimenti, F. Pratesi et al., "Prevalence and clinico-serological correlations of anti-alpha-enolase, antiC1q, and anti-dsDNA antibodies in patients with systemic lupus erythematosus," Journal of Rheumatology, vol. 33, no. 4, pp. 695-697, 2006. 


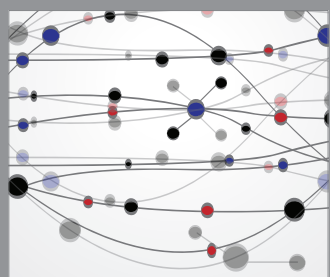

The Scientific World Journal
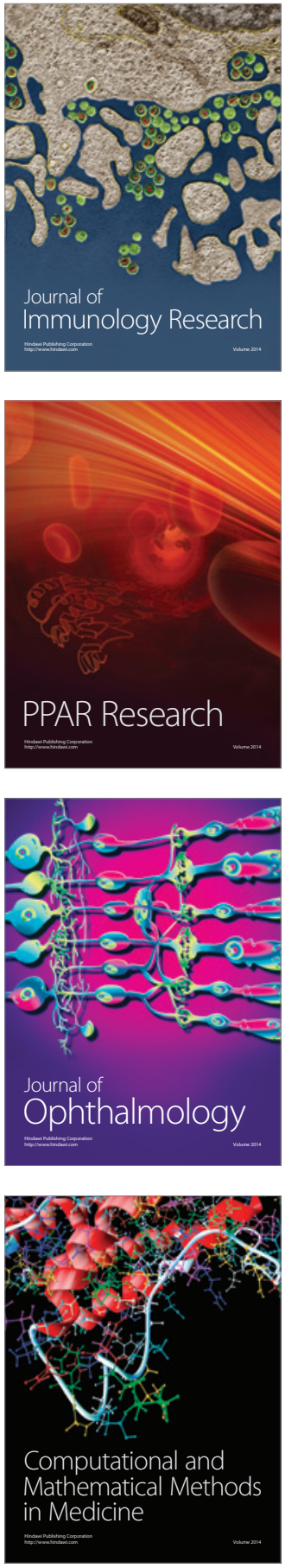

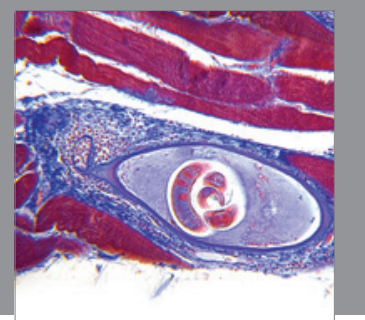

Gastroenterology

Research and Practice
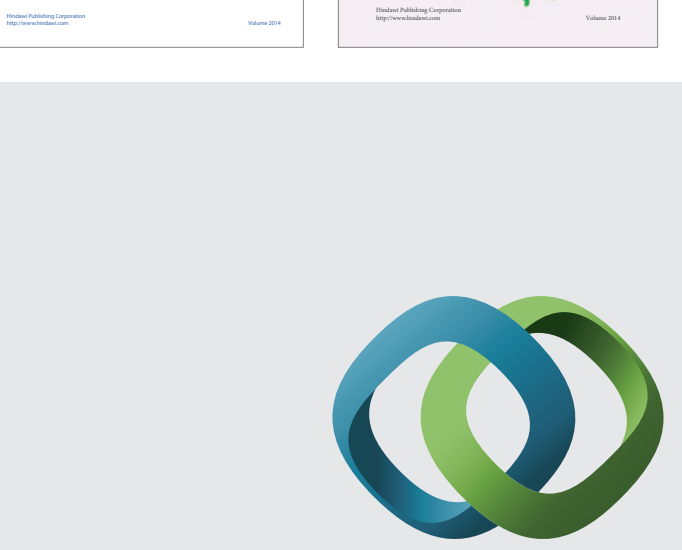

\section{Hindawi}

Submit your manuscripts at

http://www.hindawi.com
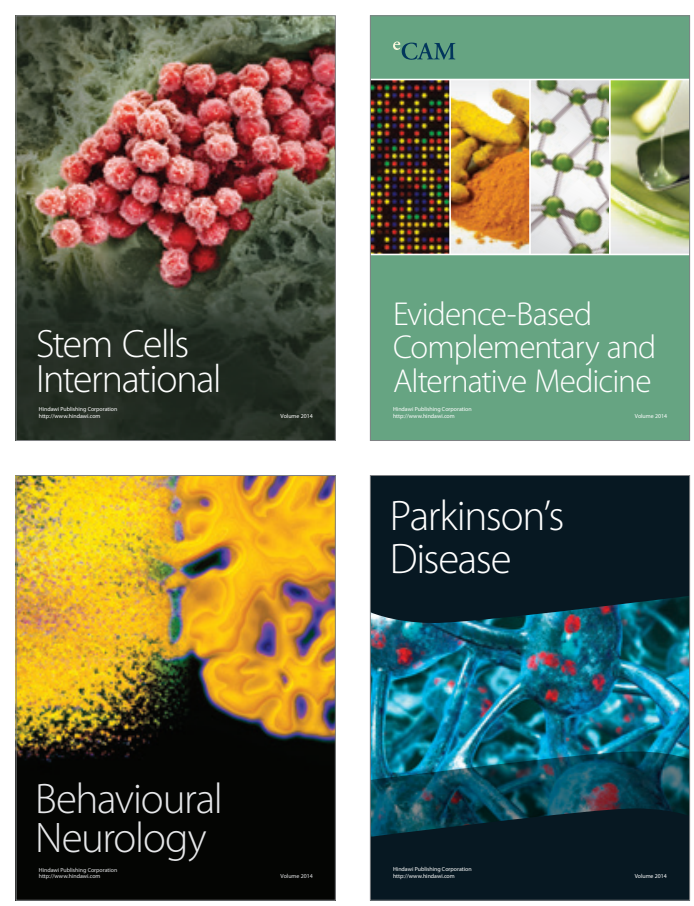

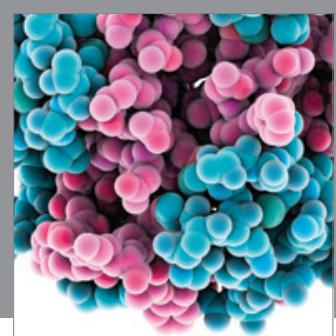

Journal of
Diabetes Research

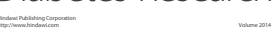

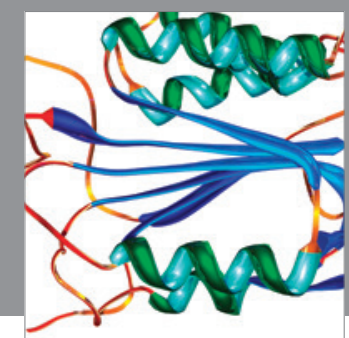

Disease Markers
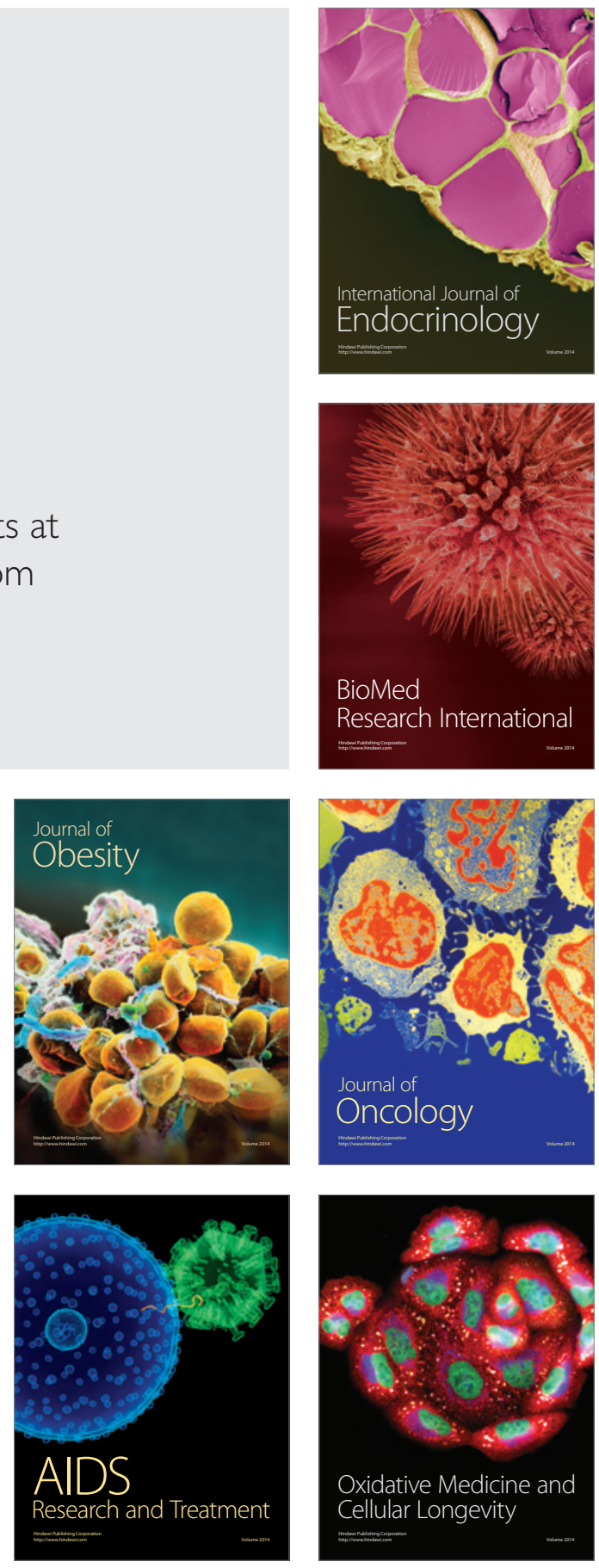